\title{
The effects of waste glass cullets and nanosilica on the long-term properties of cement mortars
}

\author{
Katarzyna Skoczylas ${ }^{1}$, and Teresa Rucińska ${ }^{1, *}$ \\ ${ }^{1}$ Department of Building Physics and Building Materials, Faculty of Civil Engineering and \\ Architecture, West Pomeranian University of Technology, Szczecin, al. Piastow 50, 70-310 \\ Szczecin, Poland
}

\begin{abstract}
This study presents experimental results on the effects of nanosilica and waste glass cullets on the long-term mechanical properties and durability of cement mortars. Three groups of cement mortars were prepared, where natural aggregate was replaced in $0 \%(\mathrm{R}), 50 \%$ (RWG) and $100 \%$ (WG) with waste glass cullets by volume. Each group was modified with the nanosilica admixture by $0 \%, 1 \%$ and $3 \%$ by the weight of cement. Furthermore, superplasticizer was incorporated in order to improve the workability of mortars. Subsequently to the preparation and curing of specimens, mechanical properties after 7, 28 and 365 days, freeze-thaw resistance, adhesive strength, abrasion resistance, and drying shrinkage (in two types of curing conditions) were evaluated. The results confirmed the applicability of waste glass in the construction industry as well as the beneficial effect of nanosilica on the mechanical properties of mortars.
\end{abstract}

\section{Introduction}

The rapid civilizational progress contributes to the natural environment degradation. Taking this issue into consideration, the idea of sustainable development has been evolving for the interest of future generations. In addition, The European Union established strict requirements regarding sustainable development that significantly emphasise the secondary processing. The emerging problem with municipal and construction waste is constantly growing in every European country. By the decision of the European Parliament [1], a community action program was established in the field of the environment that encourages activities aimed at reducing waste and taking care of the environment. These include: a reduction in the amount of generated waste, a more efficient use of resources during production, avoiding the increase of pollutant emissions during the utilization and production of waste, and waste recycling. By 2020, Poland is expected to reach up to a $50 \%$ recycling threshold, and up to $65 \%$ in 2030 [2].

Soda-lime glass is a type of glass that is widely used in glass containers for storing beverages, food, and some commodity items. It should be highlighted that recycling of this type of glass in Europe is on a relatively high level. Moreover, even up to $85 \%$ of glass containers are obtained from the recycling process in some European countries [3]. Theoretically, glass can be recycled to infinity, without alteration in its chemical composition.

* Corresponding author: Teresa.Rucinska@zut.edu.pl 
The incorporation of waste glass cullets to concrete possibly increases the risk of alkali silica reaction (ASR) [4] that can be detrimental to concrete stability. In order to suppress the ASR, various mineral admixtures and additives including ground granulated blast-furnace slag, silica fume and fly ash are incorporated. Similarly, nanomaterials have been recently introduced as admixtures improving mechanical properties, durability, or various other properties to cementitious composites, such as self-cleaning and antibacterial activity [5]. In addition, nanomaterials were also introduced as admixtures decreasing the threat of ASR. Significant interest was given to the use of nanosilica for that purpose. Zeidan et al. [6] reported that the ASR was not observed after nanosilica incorporation to cement mortars. Aly et al. [7] reported that combination of nanosilica with waste glass powder enabled to exclude the possibility of ASR occurrence. Further, studies on the combined effect of waste glass and nanosilica are still on-going. In the recent studies by Sikora et al. [8] and Chung et al. [9], it was reported that nanosilica can have a beneficial effect on the decrement of sorptivity and thermal conductivity of cement mortars as well as concretes containing waste glass, in comparison to conventional cement-based composites with natural aggregate. In addition, it was reported that the incorporation of nanosilica contributed to a noticeable improvement in the mechanical properties of cement mortars containing waste glass aggregate [10].

The main goal of this study was to characterize the long-term properties of cement mortars containing waste glass aggregate and nanosilica admixture in variable ratio.

\section{Methodology}

\subsection{Materials}

Natural fine aggregate (river sand) from the Bielinek mine (Poland) and waste glass aggregate were used for mortar preparation together with CEM I 42.5 provided by Gorazdze Cement S.A. Waste glass was obtained from a local recycling company. Broken brown soda-lime waste glass previously used for beverage containers was washed and milled. Afterwards, glass cullets were sieved to five different fractions (Fig. 1). The percentage share of individual glass cullet fractions was adapted to the Standard Sand grain size distribution conforming CEN standard. Additionally, tap water, polycarboxylate ether (PCE) based superplasticizer, and amorphous nanosilica suspension containing 20\% of solid mass ( $80 \%$ of suspension is considered as a mixing water in this study) were used.
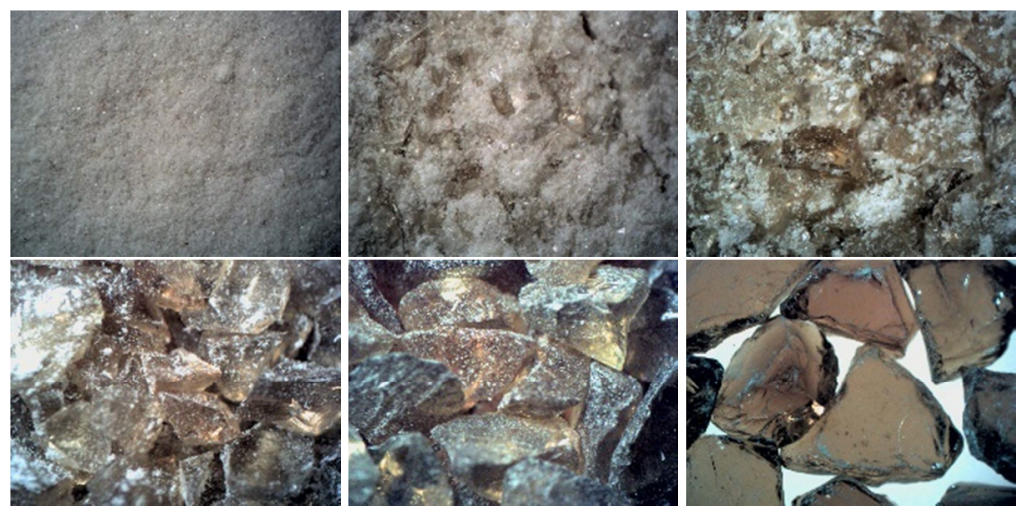

Fig. 1. Waste glass aggregate after sieving into fractions. 


\subsection{Mixture compositions and mortars preparation}

Cement mortars were prepared with a cement:water:aggregate mass ratio equal to 1:0.5:3. Three groups of mortars with different aggregate composition were prepared. The first group of mortars contained $100 \%$ of natural aggregate replaced with waste glass cullets (WG). The second group contained $50 \%$ of natural aggregate replaced with waste glass cullets (RWG), while the third group contained $100 \%$ of natural aggregate (R). In addition, every group of mortars was incorporated with a nanosilica admixture of $0 \%, 1 \%$ and $3 \%$ (by weight of cement). The amount of mixing water was proportionally reduced to the amount of water contained in the nanosilica suspension. In order to achieve a reasonable consistency, superplasticizer was incorporated. Mixture compositions are presented in Table 1.

Table 1. Mixture compositions.

\begin{tabular}{|l|c|c|c|c|c|c|c|c|c|c|}
\hline \multirow{2}{*}{ Components content } & \multicolumn{70}{|c|}{ Sample designation } \\
\cline { 3 - 13 } & & WG0 & WG1 & WG3 & RWG0 & RWG1 & RWG3 & R0 & R1 & R3 \\
\hline Cement & {$\left[\mathrm{kg} / \mathrm{m}^{3}\right]$} & 519 & 519 & 519 & 519 & 519 & 519 & 519 & 519 & 519 \\
\hline Water & {$\left[\mathrm{kg} / \mathrm{m}^{3}\right]$} & 257 & 239 & 197 & 257 & 239 & 197 & 257 & 239 & 197 \\
\hline Waste glass & {$[\%]$} & 100 & 100 & 100 & 50 & 50 & 50 & - & - & - \\
\hline River sand & {$[\%]$} & - & - & - & 50 & 50 & 50 & 100 & 100 & 100 \\
\hline Nanosilica & {$\left[\mathrm{kg} / \mathrm{m}^{3}\right]$} & - & 26 & 78 & - & 26 & 78 & - & 26 & 78 \\
\hline Superplasticizer & {$\left[\mathrm{kg} / \mathrm{m}^{3}\right]$} & 3.6 & 3.6 & 3.6 & 1.6 & 1.6 & 1.6 & 1.6 & 1.6 & 1.6 \\
\hline
\end{tabular}

Specimens were prepared conforming PN-EN 196-1 with the use of standardized automatic mortar mixer. After mixing, molds were poured with fresh mortar and mechanically compacted. In the next step, molds were stored for 24 hours in stable conditions in a water bath at $20^{\circ} \mathrm{C}$ and the relative humidity $\mathrm{RH} \geq 95 \%$. After demolding, one group of specimens was cured in the same curing conditions, while another group of mortars was cured in the climate chamber with a constant temperature of $20^{\circ} \mathrm{C}$ and $\mathrm{RH}=50 \%$.

\subsection{Test methods}

Mechanical properties were determined on six prisms with sizes of $40 \times 40 \times 160 \mathrm{~mm}$ after 7, 28 and 365 days, according to PN-EN 1015-11. A freeze-thaw resistance test was conducted conforming PN-B-04500:1985. For this purpose, six $40 \times 40 \times 160 \mathrm{~mm}$ prisms of each mortar type were prepared. Three specimens were used as the control samples (stored in a climate chamber), while another 3 prisms were subjected to 100 cycles of freezing $(4 \mathrm{~h})$ and thawing $(4 \mathrm{~h})$. Afterwards, the samples were dried to a constant mass, and flexural as well as compressive strength were determined. Based on these results, the strength loss after freeze-thaw cycles was calculated in comparison to the control specimens. The adhesion test of cement mortar with the pull-off method was conducted conforming PN-EN 1015-12. The test was carried out on a ceramic substrate, using $65 \times 120 \times 250 \mathrm{~mm}$ solid bricks. Two measuring points were made on each brick, giving the total number of 6 measurement points for each mortar. The determination of abrasion resistance was conducted on cubic samples in the size of $71 \pm 1.5 \mathrm{~mm}$ with the use of a Böhme abrasion wheel tester conforming PN-EN 1338:2003 standard.

The drying shrinkage of $40 \times 40 \times 160 \mathrm{~mm}$ cement mortar prisms was measured with the use of a Graf-Kaufman device conforming to the procedure presented in PN-B-04500:1985. 
The cement mortars were divided into two groups. The first group was stored in a climate chamber at a fixed temperature of $20^{\circ} \mathrm{C} \pm 1^{\circ} \mathrm{C}$, a relative humidity of $\mathrm{RH}=50 \pm 2 \%$ and measured up to 365 days of curing. The second group was stored in a water bath at a fixed temperature of $20^{\circ} \mathrm{C} \pm 1{ }^{\circ} \mathrm{C}$ and a relative humidity $\mathrm{RH}=95 \%$, and measurements were conducted for 120 days.

\section{Results and discussion}

\subsection{Long-term flexural strength and compressive strength}

Figures 2 and 3 present flexural and compressive strength after 7, 28 and 365 days of curing, respectively.

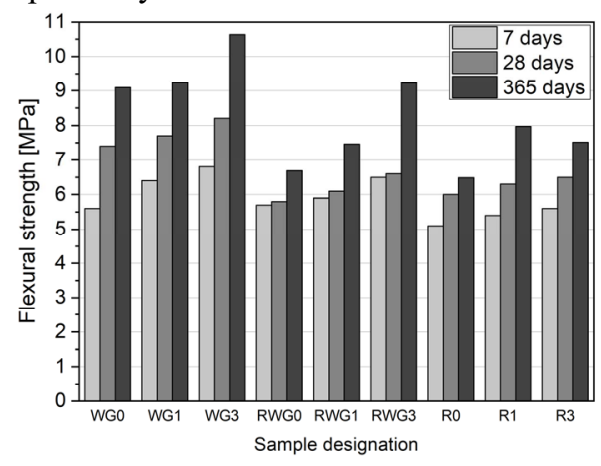

Fig. 2. Flexural strength after 7, 28 and 365 days of curing.

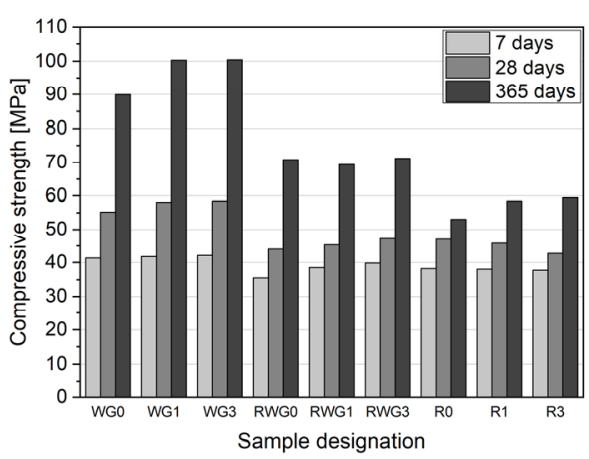

Fig. 3. Compressive strength after 7, 28 and 365 days of curing.

For all tested cement mortars the highest increment in flexural strength occurred in the first seven days of curing. All tested specimens gained at least $76 \%$ of their 28 -day strength and $62 \%$ of their year-strength. Clearly, the effect of incorporation of CEM I $42.5 \mathrm{R}$ was noticeable. Therefore, after 7 days of curing, all specimens exhibited comparable strength, whereas after 28 days of curing, a positive effect of waste glass cullets was observed. It was clear that a $100 \%$ replacement of natural sand with waste glass contributed to the increment of flexural strength by $14-21 \%$ in comparison to the respective mortars containing $100 \%$ of natural sand.

In the case of compressive strength, after 7 days of curing mortars exhibited at least $75 \%$ of their 28 -day strength and at least $46 \%$ of their year-strength. Nevertheless, the beneficial effect of incorporation of waste glass was observed after 28 days of curing. Specimen WG0 in comparison with R0 exhibited a $29 \%$ increment in compressive strength after 28 days of curing, while after 1 year of curing the strength was higher by $51 \%$. The improvement in mechanical properties of cement mortars and concretes containing waste glass cullets as a sand replacement were confirmed in many studies [11-12], however, some authors reported a strength decrement after the addition of waste glass to the mix [13].

It can be also observed that the incorporation of nanosilica has a beneficial effect on the improvement of mechanical properties of cement mortars. These results are in accordance with other available studies [14]. It was reported that nanosilica exhibits a high pozzolanic activity resulting in the production of additional strength giving C-S-H phase. In addition, nanosilica ehxibits a pore-filling effect and compacts the microstructure which contributes to the strength improvement $[8,15-16]$. In cement mortars containing waste glass (WG) incorporated with $1 \mathrm{wt} \%$ and $3 \mathrm{wt} \%$ of nanosilica contributed to the strength improvement by $14 \%$ and $21 \%$ after 7 days of curing, by $4 \%$ and $11 \%$ after 28 days of curing, and by $2 \%$ 
and $17 \%$ after 365 days of curing, in comparison with plain mortar, respectively. In the case of RWG mortars, the reported strength improvement was within the range of $8 \%$ to $38 \%$. $\mathrm{R}$ mortars exhibited the lowest compressive strength among all tested specimens. However, the beneficial effect of nanosilica incorporation was observed from the $28^{\text {th }}$ day of curing. These results were partially presented in an article by Sikora et al. [8].

\subsection{Freeze-thaw resistance}

After 100 freeze/thaw cycles, R0 mortars exhibited a surface spalling and damage (Fig. 4). Therefore, the mechanical properties of these samples could not be determined. The macroscopic analysis confirmed noticeable cracks on the surface of the specimens containing solely natural aggregate (R0). The WG0 specimens showed surface exfoliation (Fig. 5).

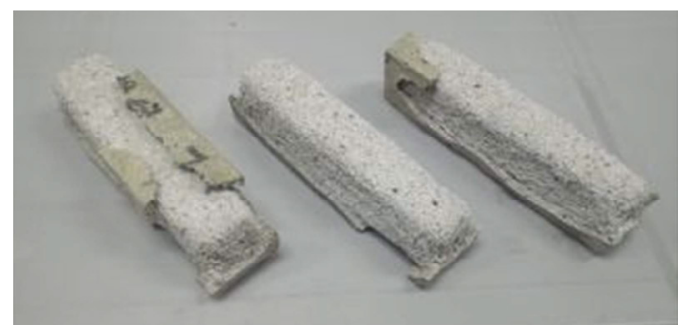

Fig. 4. R0 mortar samples that were destroyed during thawing and defrosting cycles.

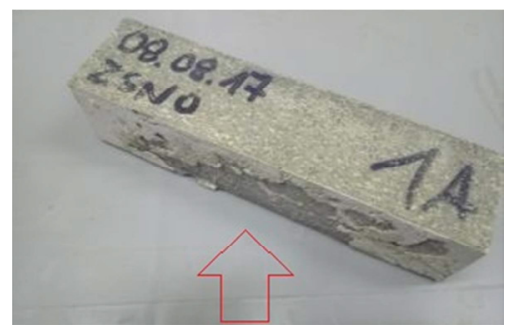

Fig. 5. Surface exfoliation on a WG0 mortar sample.

Figure 6 presents the percentage loss of compressive strength in specimens after 100 freeze/thaw cycles. The percentage loss was calculated by dividing the compressive strength value of samples after freezing and thawing cycles by compressive strength of control mortars. The lowest strength loss was reported for the WG3 specimen. In general, cement mortars containing $100 \%$ of waste glass cullets (WG) exhibited the best performance among all tested specimens. The loss of compressive strength was within the range of $6 \%$ to $7.6 \%$. Replacement of $50 \%$ of natural sand with waste glass (RWG) also contributed to the retention of strength loss where the strength loss was within a range between 12.5 and $15.9 \%$. The samples containing natural aggregate $(\mathrm{R})$ exhibited the worst performance. As mentioned above, sample R0 was damaged during the freeze-thaw test, while R1 and R3 mortars exhibited significant strength loss by $31.1 \%$ and $31.2 \%$, respectively. According to the referred testing procedure, the acceptable strength loss of mortars should be less than $20 \%$.

In addition, the beneficial effect of nanosilica was observed. The incorporation of nanosilica to R mortars prevented the cracking in mortars R1 and R3. In the other groups of mortars (RWG and WG) nanosilica contributed to a decrement in strength loss. Similar findings were reported in other studies [15], where concrete containing $3 \%$ of nanosilica exhibited $28 \%$ of strength loss after 300 cycles of freezing and thawing, while concrete without nanosilica was damaged and could not be tested. The R0 specimen, containing $100 \%$ of natural sand, was damaged after 100 freeze/thaw cycles. However, the incorporation of nanosilica improved the structure of R1 and R3 mortars, and samples exhibited only a slight mass loss by $0.18 \%$ and $0.49 \%$, respectively. In the case of other plain mortars, the mass loss was within 0.26 and $0.35 \%$. According to the testing procedure, the acceptable mass loss in samples should not exceed $5 \%$. 


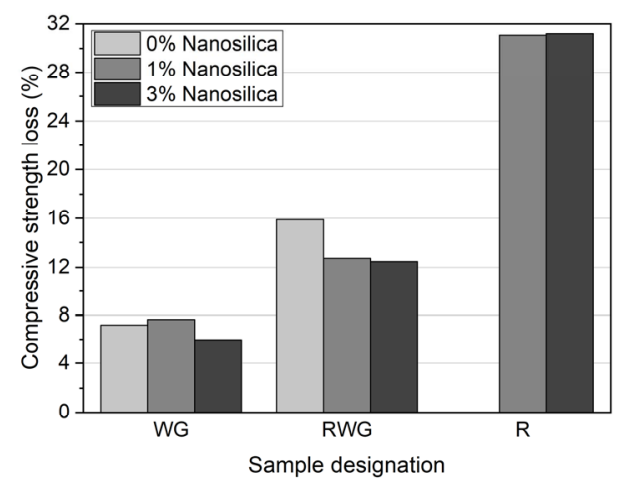

Fig. 6. Compressive strength loss in cement mortars after 100 freeze-thaw cycles.

\subsection{Adhesion}

Table 2 presents the adhesive strengths of cement mortars determined with the pull-off method. In all tested mortars, the average adhesive strength values were higher than $0.6 \mathrm{MPa}$. The lowest strength was represented for mortars RWG1 $(50 \%$ natural aggregate $+50 \%$ of waste glass cullets $+1 \%$ of nanosilica) and R3 (100\% of natural aggregate and $3 \%$ of nanosilica). Together with the increment in nanomaterial content, the crack model changed its character from cohesion to adhesion and a crack occurred at the interface between the mortar and ceramic substrate. Nanosilica decrease the workability of cement mortar due to its high water demand [17], resulting in a weaker connection with the surface. In addition, nanosilica contributed to the increment in shrinkage leading to the occurrence of shear stress in the plane of interface between the mortar and substrate.

Table 2. Adhesive strengths of cement mortars determined with pull-off method.

\begin{tabular}{|c|c|c|}
\hline \multirow{2}{*}{$\begin{array}{c}\text { Sample } \\
\text { designation }\end{array}$} & Crack model & Test results pull-off \\
\cline { 3 - 3 } & & [MPa] \\
\hline WG0 & cohesion & 1.7 \\
\hline WG1 & cohesion & 1.8 \\
\hline WG3 & adhesion & 1.4 \\
\hline RWG0 & cohesion & 0.9 \\
\hline RWG1 & adhesion & 0.6 \\
\hline RWG3 & adhesion & 1.3 \\
\hline R0 & cohesion & 1.8 \\
\hline R1 & adhesion & 1.4 \\
\hline R3 & adhesion & 0.6 \\
\hline
\end{tabular}

\subsection{Abrasion resistance}

The abrasion test results are presented in Figure 7. No significant difference was observed between the type of aggregate used and the depth of wear. The incorporation of nanosilica contributed to the increment in the abrasion resistance of cement mortars. With the incorporation of $1 \mathrm{wt} \%$ of nanosilica the depth of wear decreased by $6.8-8.9 \%$ in comparison to the respective plain mortars, while the incorporation of $3 \mathrm{wt} \%$ of nanosilica improved the abrasion resistance by 11.4 to $15.6 \%$ depending on the group of mortars. 


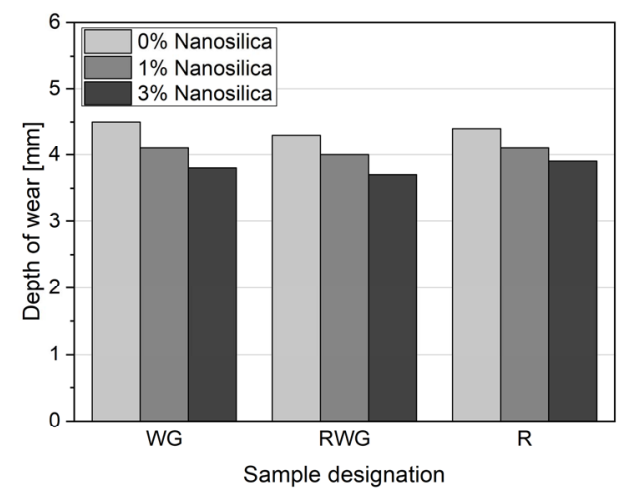

Fig. 7. Depth of wear.

\subsection{Drying shrinkage}

Drying shrinkage (described also as a volume change) was determined in two different curing conditions. Figure 8 depicts the results of drying shrinkage of mortars cured at $20^{\circ} \mathrm{C}$ and $\mathrm{RH}=50 \%$. It was observed that the drying shrinkage of mortars significantly increased in the first days of curing and slowly stabilized after 28 days. The analysis of drying shrinkage in the first 10 days of curing showed that the highest drying shrinkage was observed in the case of cement mortars containing waste glass (WG). In addition, the $3 \mathrm{wt} \%$ incorporation of nanosilica had a significant effect on the increment in the drying shrinkage of cement mortars, which is in consistency with previous findings $[18,19]$. The incorporation of waste glass contributed to the increment in the drying shrinkage ratio. However, these findings are contrary with previous findings [20,21], stating that the incorporation of waste glass can reduce the shrinkage due to the more impermeable surface of aggregates. The highest value of drying shrinkage was observed for specimen RWG3, whereas the lowest for RWG0. This could be attributed to the interaction of two types of aggregates, i.e., natural aggregate expressing the round shape of particles and waste glass cullets characterized by elongated and needle-shaped grains.

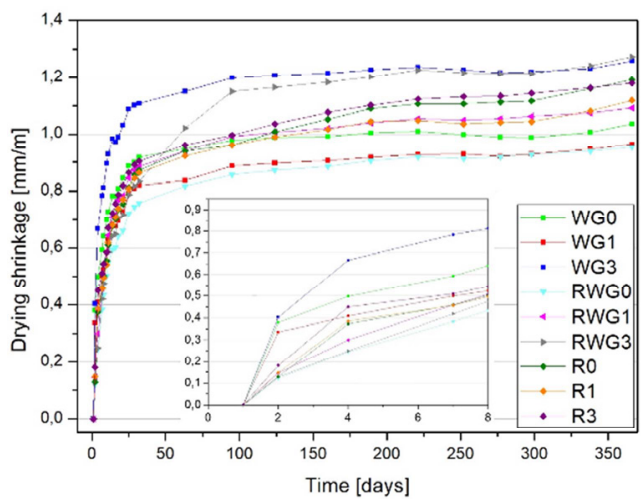

Fig. 8. Drying shrinkage of cement mortars cured in $20^{\circ} \mathrm{C}$ and $\mathrm{RH}=50 \%$ conditions.

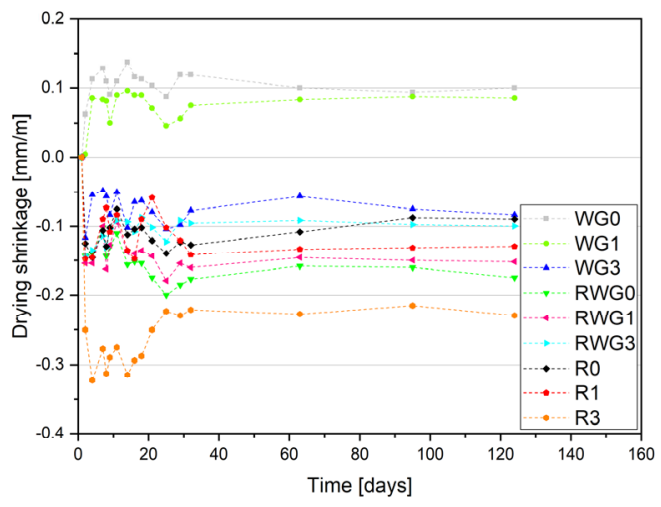

Fig. 9. Drying shrinkage of mortars cured in $20^{\circ} \mathrm{C}$ and $\mathrm{RH}=95 \%$ conditions.

The second group of specimens were stored in the water bath at $20^{\circ} \mathrm{C} \pm 1$ and $\mathrm{RH}=95 \%$. Samples were tested for 120 days. The results are shown in Figure 9. It could be observed that only mortars WG0 and WG1 exhibited drying shrinkage. Other cement mortars showed 
expansion. Beneficial moisture conditions were responsible for the elimination of drying shrinkage. The decrement in surface water and possible surface water sorption [22] during the first 30 days of curing showed noticeable variation in the shrinkage of mortars. After 30 days of curing this phenomenon was stabilized. Similar observations were reported by Domagała [23]. The effect of nanosilica on the drying shrinkage in these conditions was negligible during the whole curing period.

\section{Conclusions}

This paper presents the evaluation of waste glass aggregate and nanosilica on the long-term properties of cement mortars. Based on the experimental results, we conclude that:

1) Replacement of fine natural aggregate with waste glass cullets modified with nanosilica has a beneficial effect on the mechanical properties of cement mortars.

2) Waste glass aggregate as well as nanosilica have a beneficial effect on the freeze-thaw resistance of cement mortars contributing to a decrease in the strength loss of specimens after freeze/thaw cycles.

3) Higher content of nanosilica contributes to a decrease in the adhesive strength of cement mortar measured with a ceramic substrate.

4) Nanosilica admixture improves the abrasion resistance of cement mortars.

5) Drying shrinkage of cement mortars increases together with the increment of nanosilica content. In addition, waste glass cullets contribute to the increment in drying shrinkage.

6) Fluctuations in the relative humidity that occurs during cement mortar curing in a water bath confirms that proper humidity and temperature have a positive effect on limiting the volume changes in mortars undergoing the curing process.

Acknowledgement. This research was funded by the National Centre for Research and Development within SEFICRAOM 2/KONNECT/2016 (KONNECT Joint Call).

\section{References}

1. Decision No 1600/2002/EC of the European Parliament and of the Council of 22 July 2002, Brussels (2002)

2. E. Kołaczek, (Nowy system gospodarki odpadami komunalnymi, Ministerstwo Środowiska Warszawa (2012)

3. A. Kuśnierz, (Recykling szkła, Prace Instytutu Ceramiki i Materiałów Budowlanych, T. R 3/6, 22-33, 2010)

4. A. Shayan, Xu Aimin, Cem. and Concr. Res. 34, 81-89 (2004)

5. M. Zeidan, A.M. Said, J. Sustain. Cem.-Based Mater., 6 (2), 126-138 (2017)

6. P. Sikora, A. Augustyniak, K. Cendrowski, P. Nawrotek, E. Mijowska, MDPI, Nanomaterials 8, 212 (2018)

7. M. Aly, M.S.J. Hashmi, A.G. Olabi, Mater. Des., 33, 127-135 (2012)

8. P. Sikora, E. Horszczaruk, K. Skoczylas, T. Rucinska, Procedia Eng. 196, 159-166 (2017)

9. S.-Y. Chung, M. Abd Elrahman, P. Sikora, T. Rucinska, E. Horszczaruk, D. Stephan, MDPI, Materials 10 (12), 1354 (2017)

10. P. Sikora, A. Augustyniak, K. Cendrowski, E. Horszczaruk, T. Rucinska, P. Nawrotek, E. Mijowska, MDPI, Materials 9, 701 (2016)

11. M. Batayneh, I. Marie, I. Asi, Use of selected waste materials in concrete mixes, Waste Manag. (N.Y.) 27(12), 1870-1876 (2007)

12. Z. Z. Ismail, E. A. Al-Hashmi, Waste Manag. (N.Y.) 29, 655-659 (2009) 
13. I.B. Topcu, M. Canbaz, Cem. and Concr. Res., 34, 267-274 (2004)

14. E. Horszczaruk, P. Sikora, K. Cendrowski, S. Mijowska, P. Sikora, Constr. and Build. Mat. 137, 420-431 (2017)

15. K. Behfarnia, N. Salemi, Constr. and Build. Mat. 48 (11), 580-584 (2013)

16. P. Sikora, P. Łukowski, K. Cendrowski, E. Horszczaruk, E. Mijowska, Procedia Eng. 108, 139-145 (2015)

17. P. Sikora, E. Horszczaruk, T. Rucińska, 7th Scientific-Tech. Conf. Mat. Problems in Civil Eng. (MATBUD’2015), Procedia Eng. 108, 146-153 (2015)

18. H. Yang, 2nd International Conf. on Electronic \& Mechanical Eng. and Information Tech., EMEIT (2012)

19. Y. Chen, Y-f. Deng, M-q Li, Adv. Mater. Sci. Eng. 2016, 1-8 (2016)

20. E. Kisacik, BS Thesis, Osmangazi University, Faculty of Eng. and Arch., Dept. of Civil Eng, 52 (2002)

21. A.M. Rashad, Const. Build. Mater., 72, 340-357 (2014)

22. A. Siwińska, J. Strzałkowski, Energy Procedia 78, 1437-1442 (2015)

23. L. Domagała, Czasopismo Techniczne. Budownictwo 105 (1-B), 21-40 (2008) 